\title{
QUEEN'S
UNIVERSITY
BELFAST
}

\section{Comparative assessment of visible light and UV active photocatalysts by hydroxyl radical quantification}

Nagarajan, S., Skillen, N. C., Fina, F., Zhang, G., Randhorn, C., Lawton, L. A., Irvine, J. T. S., \& Robertson, P. K. J. (2017). Comparative assessment of visible light and UV active photocatalysts by hydroxyl radical quantification. Journal of Photochemistry and Photobiology A: Chemistry, 334, 13-19. https://doi.org/10.1016/j.jphotochem.2016.10.034

Published in:

Journal of Photochemistry and Photobiology A: Chemistry

Document Version:

Peer reviewed version

Queen's University Belfast - Research Portal:

Link to publication record in Queen's University Belfast Research Portal

Publisher rights

(c) 2016 Elsevier Ltd. This manuscript version is made available under the CC-BY-NC-ND 4.0 license http://creativecommons.org/licenses/by$\mathrm{nc}-\mathrm{nd} / 4.0 /$ which permits distribution and reproduction for non-commercial purposes, provided the author and source are cited.

\section{General rights}

Copyright for the publications made accessible via the Queen's University Belfast Research Portal is retained by the author(s) and / or other copyright owners and it is a condition of accessing these publications that users recognise and abide by the legal requirements associated with these rights.

Take down policy

The Research Portal is Queen's institutional repository that provides access to Queen's research output. Every effort has been made to ensure that content in the Research Portal does not infringe any person's rights, or applicable UK laws. If you discover content in the Research Portal that you believe breaches copyright or violates any law, please contact openaccess@qub.ac.uk. 
1 Comparative assessment of visible light and UV active photocatalysts by hydroxyl

2 radical quantification

3 Sanjay Nagarajan ${ }^{1 *}$, Nathan C. Skillen ${ }^{1}$, Federica Fina ${ }^{2}$, Guan Zhang ${ }^{2}$, Chamnan

4 Randorn², Linda A. Lawton ${ }^{3}$, John T.S. Irvine ${ }^{2}$ and Peter K.J. Robertson ${ }^{1 *}$

$5 \quad{ }^{1}$ Centre for the Theory and Application of Catalysis (CenTACat), School of Chemistry

6 and Chemical Engineering, Queen's University Belfast, David Keir Building, Stranmillis

7 Road, Belfast, BT9 5AG, United Kingdom;

$8 \quad{ }^{2}$ JTSI Group, University of St. Andrews, School of Chemistry, Purdie Building, North

9 Haugh, St Andrews, KY16 9ST, United Kingdom;

$10{ }^{3}$ School of Pharmacy and Life sciences, Sir lan Wood Building

11 Robert Gordon University, Garthdee Road, Aberdeen, AB10 7GJ, United Kingdom

$12{ }^{*}$ Corresponding authors, p.robertson@qub.ac.uk; snagarajan01@qub.ac.uk, Tel: +44

(0) 2890974627

\section{ABSTRACT}

A simple method for determining hydroxyl radical yields on semiconductor photocatalysts is highly desirable, especially when comparing different photocatalyst materials. This paper reports the screening of a selection of visible light active photocatalysts such as $\mathrm{Pt}_{-} \mathrm{C}_{3} \mathrm{~N}_{4}, 5 \% \mathrm{LaCr}$ doped $\mathrm{SrTiO}_{3}, \mathrm{Sr}_{0.95} \mathrm{Cr}_{0.05} \mathrm{TiO}_{3}$ and Yellow $\mathrm{TiO}_{2}$ and compares them against $\mathrm{WO}_{3}$ and ultra violet (UV) light activated $\mathrm{TiO}_{2} \mathrm{P} 25$ (standard commercial catalysts) based on their oxidative strengths $(\mathrm{OH}$ radical producing capability) using a well-studied chemical probe - coumarin. 7hydroxycoumarin, the only fluorescent hydroxylation product of this reaction can then be measured to indirectly quantify the $\mathrm{OH}$ radicals produced. P25 under UV light produced the highest concentration of $\mathrm{OH}$ radicals $(16.9 \mu \mathrm{M})$, followed by $\mathrm{WO}_{3}(0.56$ $\mu \mathrm{M})$ and $\mathrm{Pt}-\mathrm{C}_{3} \mathrm{~N}_{4}(0.25 \mu \mathrm{M})$. The maximum $\mathrm{OH}$ radical production rate for $\mathrm{P} 25, \mathrm{WO}_{3}$ 
27 and $\mathrm{Pt}_{-} \mathrm{C}_{3} \mathrm{~N}_{4}$ were also determined and found to be $35.6 \mu \mathrm{M} / \mathrm{hr}, 0.28 \mu \mathrm{M} / \mathrm{hr}$ and 0.88

$28 \mu \mathrm{M} / \mathrm{hr}$ respectively. The other visible light activated photocatalysts did not produce any

$29 \mathrm{OH}$ radicals primarily as a result of their electronic structure. Furthermore, it was

30 concluded that, if any visible light absorbing photocatalysts are to be fabricated in

31 future for the purpose of photocatalytic oxidation, their $\mathrm{OH}$ radical producing rates (and

32 quantities) should be determined and compared to P25.

33 Keywords: Photocatalyst, visible light photocatalysts, OH radical, coumarin, P25.

34

35

36

37

38

39

40

41

42

43

44

45

46

47

48 


\section{INTRODUCTION}

Photocatalysis has gained significant interest since the early publication by Fujishima and Honda in 1972, demonstrating the potential of splitting water over $\mathrm{TiO}_{2}$ [1]. Since this publication, photocatalysis has been applied to a broad range of fields including waste water treatment, microbe destruction, toxin removal, energy production and air treatment. [2-8]. The mechanism of photocatalysis has been well documented and can be generally represented by the equations shown in reactions $1-9[9,10]$. The formation of surface radical species such as superoxide $\left(\mathrm{O}_{2}{ }^{--}\right)$and hydroxyl radicals $(\mathrm{OH})$ play a key role in a number of photocatalytic pathways and as such their identification and quantification is a key consideration. As shown in reaction $2, \mathrm{OH}$ radicals are primarily generated from the reaction between valence band holes $\left(h_{v b+}\right)$ and hydroxyl ions on the catalyst surface. An indirect pathway, via $\mathrm{O}_{2}{ }^{-*}$, also results in $\mathrm{OH}$ radical formation, as shown in reactions 3-6. The efficiency of $\mathrm{OH}$ radicals in photocatalytic reactions is predominantly based on their strong oxidising potential of 2.8 $\mathrm{V}$ (vs NHE) [11]. The non-selective nature of these reactive oxygen species also aids rapid degradation of various pollutants and organic contaminants [3,7,11-16].

66

67

68

Photocatalyst $+h v \rightarrow h_{v b^{+}}+e_{c b^{-}}$

$h_{v b^{+}}+\mathrm{OH}^{-}\left(\right.$or $\left._{2} \mathrm{O}\right) \rightarrow \mathrm{OH}^{\circ}$

69

$e_{c b^{-}}+O_{2} \rightarrow O_{2}^{-}$

$70 \mathrm{O}_{2}^{-}+\mathrm{H}^{+} \rightarrow \mathrm{HO}_{2}$

$71 \mathrm{HO}_{2}+\mathrm{HO}_{2} \rightarrow \mathrm{H}_{2} \mathrm{O}_{2}+\mathrm{O}_{2}$

$72 \mathrm{H}_{2} \mathrm{O}_{2}+e_{c b^{-}} \rightarrow \mathrm{OH}^{\cdot}+\mathrm{OH}^{-}$

$73 \quad \mathrm{O}_{2}^{-} \cdot$ reactants $\rightarrow$ products

$74 \quad$ substrates $+\cdot \mathrm{OH} \rightarrow$ products 
$e_{c b^{-}}+\mathrm{OH}^{\cdot} \rightarrow \mathrm{OH}^{-}$

where, $\mathrm{h}_{\mathrm{vb}}{ }^{+}$represents VB holes and $\mathrm{e}_{\mathrm{cb}}{ }^{-}$means $\mathrm{CB}$ electrons.

Newly developed photocatalytic technologies and materials have often utilised model compounds and screening methods to assess their performance [17-20]. Common evaluation methods reported in the literature include the decomposition of dyes such as methylene blue (ISO test 10678:2010), or degradation of organic pollutants such as 4-chlorophenol or toluene [17-20]. These procedures are often coupled with the corresponding calculated photonic efficiencies and quantum yields to evaluate overall efficiency. While these methods can be effective in identifying the specific photocatalytic performance of a material in relation to a fingerprint compound, they provide little information regarding the production of $\mathrm{OH}$ radicals involved within the mechanism. Therefore, the requirement for a simple and robust method of radical quantification for screening the oxidative potential of catalysts has significantly increased. The challenge in $\mathrm{OH}$ radical quantification lies in both the non-selective nature and short lifetime ( 1 nanosecond) of the radical, which restricts the possibility of direct quantification [21]. Consequently, a range of methods have been developed such as emission spectroscopy, laser induced fluorescence, electron spin resonance, spin trap and chemical probes or quencher based methods to quantify $\mathrm{OH}$ radicals [2137].

The use of a chemical probe to capture $\mathrm{OH}$ radicals presents a potentially efficient way to measure the radical due to the low cost, rapid analysis time and reproducibility of the method. Monitoring a probe compound through spectroscopy allows the concentration of $\mathrm{OH}$ radicals to be calculated based on stoichiometric ratios of products formed. A recently reported in vivo technique utilised a nanoprobe comprising of a nanoparticle and azo dye in order to quantify $\mathrm{OH}$ radicals in the femtomolar range [37]. 
Here the nanoparticle was used as an energy donor and the modified orange was used as an $\mathrm{OH}$ radical capturing ligand molecule (and the energy acceptor).

Dimethyl sulfoxide (DMSO) based methods for $\mathrm{OH}$ radical capture have also been utilised in the past to quantify these species via the formation of formaldehyde $[28,29,31]$. The formation of $\mathrm{CH}_{4}$ in a closed system coupled with $\mathrm{O}_{2}$ bubbling however reduces the suitability of utilising DMSO as a probe molecule.

In the past, $\mathrm{OH}$ radical quantification has been carried out for various commercially available photocatalysts, photo-Fenton's reaction and other modified $\mathrm{TiO}_{2}$ based visible light photocatalysts with either coumarin or terepthalic acid as probe molecules $[21,23,31-36,38,39]$. Both compounds are capable of acting as $\mathrm{OH}$ radical traps by forming fluorescent products as result of reacting with the radical species. Terepthalic acid has been investigated in a study by Ishibashi et al. which achieved an $\mathrm{OH}$ radical concentration of $7 \times 10^{-5} \mathrm{M}$ based on the measurement of 2-hydroxyterepthalic acid [35]. In addition to the use of terepthalic acid as a probe molecule, coumarin has been used in a number of studies to determine the concentration of $\mathrm{OH}$ radicals produced from $\mathrm{TiO}_{2}$ at relatively high loadings of 1 to $5 \mathrm{~g} / \mathrm{L}[21,23,40]$. For instance, Czili et al. used $100 \mu \mathrm{M}$ coumarin as the probe molecule to capture $\mathrm{OH}$ radicals under a $40 \mathrm{~W}$ UV lamp. They determined a maximum $\mathrm{OH}$ radical production rate of $23.39 \mu \mathrm{M} / \mathrm{g} / \mathrm{hr}$ (calculated from their reported 7-hydroxycoumarin rates) with $1 \mathrm{~g} / \mathrm{L} \mathrm{TiO}_{2} \mathrm{P} 25$ photocatalyst.

This paper utilises coumarin as a hydroxyl radical trap and reports the screening of a selection of visible light responsive photocatalysts under low power illumination based on their $\mathrm{OH}$ radical producing capability. In contrast to previous reports, which concentrated on quantifying the $\mathrm{OH}$ radicals produced from $\mathrm{TiO}_{2}$, other commercially 
available and a few synthesised photocatalysts $[21,23,31,40]$, this work focusses on assessing the oxidative strength of visible light photocatalytsts $\mathrm{Pt}-\mathrm{C}_{3} \mathrm{~N}_{4}, 5 \% \mathrm{LaCr}$ doped $\mathrm{SrTiO}_{3}, \mathrm{Sr}_{0.95} \mathrm{Cr}_{0.05} \mathrm{TiO}_{3}$ (referred to as $\mathrm{Cr}-\mathrm{SrTiO}_{3}$ from here on) and yellow $\mathrm{TiO}_{2}$ and compares them against commercial $\mathrm{TiO}_{2} \mathrm{P}_{2} 5$ and $\mathrm{WO}_{3}$ for evaluation. In addition, a low catalyst loading was used to highlight efficient $\mathrm{OH}$ radical formation can be achieved without requiring large quantities of powdered catalyst.

\section{EXPERIMENTAL PROCEDURE}

\subsection{Materials}

Coumarin and 7-hydroxycoumarin were purchased from Tokyo Chemical Industry UK Ltd, while $\mathrm{TiO}_{2} \mathrm{P} 25$ was purchased from Degussa (now Evonik industries) and $\mathrm{WO}_{3}$ nano powders were purchased from Sigma Aldrich. All commercial chemicals were used as received. The catalysts $\mathrm{Pt}_{-} \mathrm{C}_{3} \mathrm{~N}_{4}$ [41], 5\% $\mathrm{LaCr}$ doped $\mathrm{SrTiO}_{3}, \mathrm{Cr}-\mathrm{SrTiO}_{3}$ and yellow $\mathrm{TiO}_{2}$ [42] were synthesised at the school of chemistry, University of St. Andrews, using methods cited in the literature [41-43].

\subsection{Characterisation of Photocatalysts}

$\mathrm{WO}_{3}, \mathrm{LaCr}-\mathrm{SrTiO}_{3}$ and $\mathrm{Cr}-\mathrm{SrTiO}_{3}$ were characterised by X-Ray diffraction (XRD) and UV-Visible absorption. XRD analysis of powders was examined on a SToe STADI/P powder diffractometer. Incident radiation was generated using a Cu $\mathrm{k}_{\alpha}$ source $(\lambda=1.54056 \AA)$. Diffuse reflectance spectra were collected on a JASCO-V550 UVvisible spectrophotometer. The characterisation of $\mathrm{Pt}-\mathrm{C}_{3} \mathrm{~N}_{4}$ and yellow $\mathrm{TiO}_{2}$ has been reported elsewhere in literature $[41,42]$.

\subsection{Photocatalytic experiments}

All photocatalytic experiments were performed in closed screw cap bottles. The reaction solution was composed of $100 \mathrm{ml}$ of $100 \mu \mathrm{M}$ coumarin along with $10 \mathrm{mg}$ of 
156 photocatalyst $(0.1 \mathrm{~g} / \mathrm{L})$. A magnetic stirrer bar was placed inside the bottle and the

157 bottle was then placed on a magnetic stirrer at a distance of $11 \mathrm{~cm}$ from a $36 \mathrm{~W}$ compact fluorescent non-integrated visible lamp (Philips, colour code 830 ) or a $36 \mathrm{~W}$ UV lamp (Philips, Cleo lamps). The spectral outputs of the lamps were measured by a StellaNet spectrometer and the spectra are shown in the supplementary material (Figure S1). Prior to illumination, the reaction solution was stirred in the dark to allow a state of equilibrium to be reached. The length of time required in the dark was calculated from the control experiments conducted in the absence of light. During irradiation, samples $(3 \mathrm{~mL})$ were taken at dedicated time intervals for a maximum of 120 mins. Samples were filtered through a $0.22 \mu \mathrm{m}$ Millex syringe filter prior to analysis. Coumarin absorbance was monitored using a Cary 300 Scan, UV-Visible Spectrophotometer at $277 \mathrm{~nm}$, with a scan rate of $400 \mathrm{~nm} / \mathrm{min}$. 7-hydroxycoumarin fluorescence was measured in a PerkinEImer LS 50B luminescence and Figure S3. All experiments were performed in triplicate. time during this photocatalytic process was calculated using the following equation.

\subsection{OH radical quantification}

$\mathrm{OH}$ radicals were quantified based on a modified method described by Zhang et al. [38] and according to equation 1. The concentration of $\mathrm{OH}$ radicals was calculated by assuming that $6.1 \%$ of total $\mathrm{OH}$ radicals were captured as 7 -hydroxycoumarin. The stoichiometric ratio of one mole of $\mathrm{OH}$ radical consumed for the production of one mole of 7-hydroxycoumarin was used [23]. The total number of $\mathrm{OH}$ radicals produced over 
Where, $\mathrm{X}$ is the total $\mathrm{OH}$ radical concentration $(\mu \mathrm{M})$ produced during photocatalysis, $\mathrm{A}$ is the mean 7-hydroxycoumarin concentration $(\mu \mathrm{M})$ and $\mathrm{B}$ is the amount of $\mathrm{OH}$ radicals $(\mu \mathrm{M})$ produced during the light control experiments. The concentration of coumarin and 7-hydroxycoumarin was calculated using a standard curve of known concentrations as shown in the supplementary material (Figure S4, Figure S5 and Figure S6).

\section{RESULTS AND DISCUSSION}

\subsection{Characterisation of Photocatalysts}

XRD patterns of $\mathrm{WO}_{3}, \mathrm{Cr}-\mathrm{SrTiO}{ }_{3}$ and $\mathrm{LaCr}-\mathrm{SrTiO}_{3}$ samples were determined as shown (Figure 1). The commercial $\mathrm{WO}_{3}$ nanoparticles exhibited a typical crystallized monoclinic phase structure, and the $\mathrm{Cr}$-doped and $\mathrm{La}, \mathrm{Cr}$-co-doped $\mathrm{SrTiO}_{3}$ samples possessed homogeneous crystallized cubic perovskite structures, with no impurity phase found for either of the doped samples and these results were consistent with literature $[44,45]$. In the co-doped samples, since $\mathrm{La}$ and $\mathrm{Cr}$ substitute the $\mathrm{Sr}$ and $\mathrm{Ti}$, respectively, and the radius of $\mathrm{La}$ is similar with that of $\mathrm{Sr}$ while the radius of $\mathrm{Cr}$ was similar to that of $\mathrm{Ti}$, the peak positions of the $\mathrm{Cr}_{-}-\mathrm{SrTiO}_{3}$ and $\mathrm{LaCr}-\mathrm{SrTiO}{ }_{3}$ samples are not shifted compared to those of pure $\mathrm{SrTiO}_{3}$.

Figure 1.

In the UV-visible absorption spectra of $\mathrm{WO}_{3}, \mathrm{Cr}_{-} \mathrm{SrTiO}_{3}$ and $\mathrm{LaCr}-\mathrm{SrTiO}_{3}$ (Figure

2), $\mathrm{WO}_{3}$ exhibited visible light absorption up to $470 \mathrm{~nm}$, which corresponds to the bandgap energy of ca. $2.64 \mathrm{eV} . \mathrm{SrTiO}_{3}$, however, has no absorption in the visible light region (bandgap of $3.75 \mathrm{eV}$ ) and metal-doping has been shown to be a feasible method for extending the light absorption of $\mathrm{SrTiO}_{3}$ into the visible region [46]. Doping 
of $\mathrm{Cr}$ into the $\mathrm{A}$-site of $\mathrm{SrTiO}_{3}$ induces an absorption band in the visible region centred at around $450 \mathrm{~nm}$ (Figure 2). The visible light absorption is ascribed to the electron excitation from the $\mathrm{Cr}$ doping levels formed above the valence band of $\mathrm{SrTiO}_{3}$ to the conduction band of $\mathrm{SrTiO}_{3}$ [43]. It was reported that $\mathrm{La}, \mathrm{Cr}$ - co-doped $\mathrm{SrTiO}_{3}$ showed enhanced photocatalytic performance compared to the single $\mathrm{Cr}$-doped $\mathrm{SrTiO}_{3}$ due to the inhibition of the formation of $\mathrm{Cr}^{6+}$ species in the $\mathrm{B}$ site [43]. Therefore, a co-doped sample, $\mathrm{LaCr}-\mathrm{SrTiO}_{3}$ was prepared by the same method. The visible light absorption of $\mathrm{LaCr}-\mathrm{SrTiO}_{3}$ was significantly enhanced compared to the $\mathrm{Cr}-\mathrm{SrTiO}_{3}$, with two strong absorption peaks centred at around $450 \mathrm{~nm}$ and $650 \mathrm{~nm}$ in the visible light region. In the case of co-doping, more intermittent doping levels are formed within the band-gap of $\mathrm{SrTiO}_{3}$ compared to the single $\mathrm{Cr}$ doped $\mathrm{SrTiO}_{3}$, which results in the visible light absorption.

\section{Figure 2.}

\subsection{Photocatalytic $\mathrm{OH}$ radical production}

\subsubsection{UV light photocatalysis on P25}

P25 has been one of the most extensively investigated and most active commercially available photocatalysts under UV irradiation and therefore was used as a benchmark for comparison in this study. Although, recent studies have reported that nano-spherical $\mathrm{InCrO}_{4}$-loaded $\mathrm{TiO}_{2}$ and $\mathrm{TiO}_{2}$ nanospheres deposited on graphene performed better than $\mathrm{P} 25$ for $\mathrm{OH}$ radical production and dye degradation upon UV irradiation $[47,48]$, to date P25 is still regarded as the benchmark. The photocatalytic hydroxylation of coumarin over P25 under UV light and subsequent formation of 7hydroxycoumarin is shown in Figure 3. The production of 7-hydroxycoumarin under these conditions equates to a peak $\mathrm{OH}$ radical concentration of $16.9 \mu \mathrm{M}$ after 45 mins. 
Figure 3.

As shown in the figure, near complete degradation (97\%) of coumarin was achieved after 120 mins irradiation. This level of degradation was likely to result from the increased adsorption of coumarin onto the catalyst, which facilitated the reaction with surface bound $\mathrm{OH}$ radicals. The role of surface bound radicals and those that are present in bulk has been highlighted in a previous publication by Li et al. [49], who investigated acid orange oxidation over $\mathrm{TiO}_{2} \mathrm{P} 25$ and $\mathrm{AgBr}$. This group investigated the quenching of $\mathrm{OH}$ radicals at the catalyst surface and in bulk in order to demonstrate that surface bound species were the predominant radicals in the oxidation pathway. This observation confirmed that increased adsorption of the substrate on the catalyst surface can significantly increase the degradation efficiency.

Figure 3 also shows the profile of 7-hydroxycoumarin production and decomposition which indirectly indicates the quantity of $\mathrm{OH}$ radicals generated. 7hydroxycoumarin concentration peaked at 45 minutes, with a maximum concentration of $1.045 \mu \mathrm{M}$, which was equivalent to $16.9 \mu \mathrm{M} \mathrm{OH}$ radicals (as calculated from equation 1). It was observed that an average production rate of $1.8 \mu \mathrm{M} / \mathrm{hr}$ was achieved during the first 45 mins, followed by an average degradation rate of 0.46 $\mu \mathrm{M} / \mathrm{hr}$ during the latter stages of irradiation. The decrease in concentration of 7 hydroxycoumarin could also be attributed to the presence of superoxide radicals as reported by Czili and Horvath [23].

Several reports have suggested the kinetics for 7-hydroxycoumarin generation from coumarin with P25 under UV irradiation are zero order [21,23,38,50-52], however, a number of these investigations also used a high concentration of both catalyst and coumarin. Furthermore, it has been suggested that at higher concentrations of coumarin $(>100 \mu \mathrm{M})$, more UV light is absorbed by this probe and not the catalyst, 
which results in a low 7-hydroxycoumarin and $\mathrm{OH}$ radical production rate [23]. In the present study, $\mathrm{K}_{\mathrm{app}}$ which is the rate constant for the formation of 7-hydroxycoumarin was calculated to be $0.0234 \mu \mathrm{M} /$ min whereas $\mathrm{K}_{\text {dis, }}$, the rate constant for the disappearance of 7-hydroxycoumarin was calculated to be $0.0135 \mu \mathrm{M} / \mathrm{min}$. In this study we have established that both, production and degradation of 7-hydroxycoumarin followed zero order kinetics, which is agreement with previous studies.

\subsubsection{Visible light photocatalysis}

A number of visible light catalysts were also selected for comparison against P25 $\mathrm{TiO}_{2}$. While the synthesised catalysts all possessed energy band gaps that supported visible light activation, only $\mathrm{WO}_{3}$ and $\mathrm{Pt}-\mathrm{C}_{3} \mathrm{~N}_{4}$ had energy band potentials (valence band at $3.2 \mathrm{~V}$ and $1.4 \mathrm{~V}$ respectively and conduction band at $0.2 \mathrm{~V}$ and $-1.3 \mathrm{~V}$ respectively) that would facilitate $\mathrm{OH}$ radical formation either directly or indirectly as mentioned in reactions 2-6. Catalysts $\mathrm{LaCr}-\mathrm{SrTiO}_{3}, \mathrm{Cr}-\mathrm{SrTiO}_{3}$ and yellow $\mathrm{TiO}_{2}$ (valence bands at $2.7 \mathrm{~V}, 2.7 \mathrm{~V}$ and $2.6 \mathrm{~V}$ respectively and conduction bands at $-0.1 \mathrm{~V}$ for all the three photocatalysts) were selected to monitor if 7-hydroxycoumarin was formed even when the electronic structure of the catalyst was not suited to the redox potential of the reaction.

\section{The photocatalytic hydroxylation of coumarin to 7-hydroxycoumarin over $\mathrm{WO}_{3}$ and} Pt- $\mathrm{C}_{3} \mathrm{~N}_{4}$ under visible light is shown in Figure 4. As can be seen, minimal conversion of coumarin was observed over both $\mathrm{Pt}-\mathrm{C}_{3} \mathrm{~N}_{4}$ and $\mathrm{WO}_{3}$, which was also supported by the low formation of 7-hydroxycoumarin (Figure 5). $\mathrm{Pt}_{-} \mathrm{C}_{3} \mathrm{~N}_{4}$ displayed a slow yet steady conversion rate, reaching a $0.91 \%$ drop in coumarin after 120 mins of irradiation whereas, a varying coumarin concentration pattern was seen over time on $\mathrm{WO}_{3}$. It is interesting to note that there was an initial decrease in coumarin concentration followed by an increase which may be attributed to coumarin desorption from the surface of 
$291 \mathrm{WO}_{3}$. This desorption could be a result of the alteration in equilibrium in the closed

292 system due to the possible evolution of $\mathrm{O}_{2}$ from water on $\mathrm{WO}_{3}$ under visible light.

Figure 4.

295

While the decrease in coumarin concentration is low, production of $\mathrm{OH}$ radicals over Pt- $\mathrm{C}_{3} \mathrm{~N}_{4}$ and $\mathrm{WO}_{3}$ was supported by the detection of 7-hydroxycoumarin upon photocatalysis (Figure 5). When $\mathrm{WO}_{3}$ was used as the photocatalyst, there was no 7hydroxycoumarin production until 30 minutes of irradiation which could be due to the rapid recombination of the electrons and the photo generated holes. After 30 minutes, $\mathrm{OH}$ radical production was steady with a gradual generation of 7-hydroxycoumarin being observed. In the case of Pt- $\mathrm{C}_{3} \mathrm{~N}_{4}$ however, 7-hydroxycoumarin production was correlates to a rapid degradation of coumarin during the first 60 mins of irradiation.

Figure 5.

307

In contrast to $\mathrm{Pt}-\mathrm{C}_{3} \mathrm{~N}_{4}$ and $\mathrm{WO}_{3}$, the catalysts $\mathrm{LaCr}-\mathrm{SrTiO}_{3}, \mathrm{Cr}-\mathrm{SrTiO}{ }_{3}$ and yellow no detectable 7-hydroxycoumarin was recorded.

\subsubsection{Influence of photocatalysts' electronic structure and particle size on $\mathrm{OH}$} radical formation

In order to evaluate and discuss the performance of the catalysts, it is essential to consider the primary contributing factors; electronic structure and particle size. The electronic structure of the catalysts dictates the initial photo-excitation of electrons to 
higher energy levels, while the particle size dictates the concentration of photons absorbed and surface reactions between coumarin and $\mathrm{OH}$ radicals. As shown in reactions $(2)-(6), \mathrm{OH}$ radicals can occur via two routes in photocatalysis. The direct formation at the valence band requires a redox potential of $2.8 \mathrm{~V}$ vs NHE, while the indirect method occurs via the intermediate radical, $\mathrm{O}_{2}^{--}$and requires a redox potential of $-0.33 \mathrm{~V}$ vs NHE [53]. The electronic structure of the catalysts tested in this study, in relation to the redox potentials required for radical formation, are shown in Figure 6.

\section{Figure 6}

As Figure 6 shows, catalysts $\mathrm{TiO}_{2} \mathrm{P} 25, \mathrm{Pt}-\mathrm{C}_{3} \mathrm{~N}_{4}$ and $\mathrm{WO}_{3}$ possess an electronic structure which corresponds to the redox potential of $\mathrm{OH}$ radical formation via either direct or indirect mechanisms. The favourable electronic structure of $\mathrm{TiO}_{2}$ for $\mathrm{OH}$ radical formation has been well documented and is evident from the results highlighted here. The performance of $\mathrm{Pt}-\mathrm{C}_{3} \mathrm{~N}_{4}$ and $\mathrm{WO}_{3}$ for $\mathrm{OH}$ radical formation, however, has not been as well reported. The structure of $\mathrm{WO}_{3}$ with a more positive valence band suggests it is capable of generating surface $\mathrm{OH}$ radicals, however, the results obtained indicate minimal 7-hydroxycoumarin production within 2 hours. Based on the structure, it was likely an increased rate of recombination preventing $\mathrm{OH}$ radical formation via the valence band hole, due to insufficient energy to initiate a reduction reaction at the conduction band [21]. To prevent recombination and to increase the $\mathrm{OH}$ radical production, Kim et al. synthesised $\mathrm{Pt}$-doped $\mathrm{WO}_{3}$ and found that the $\mathrm{OH}$ radical production from $\mathrm{Pt}_{-} \mathrm{WO}_{3}$ was significantly higher than un-doped $\mathrm{WO}_{3}$ [20]. Furthermore, the large particle size of approximately $100 \mathrm{~nm}$ for $\mathrm{WO}_{3}$ indicates a smaller surface area, which leads to minimum absorption of light. 
The electronic structure of Pt- $\mathrm{C}_{3} \mathrm{~N}_{4}$ as seen from Figure 6 clearly indicates a

reducing catalyst, which is also supported by its application in water reduction investigations [54]. Therefore, the hydroxylation of coumarin and subsequent formation of 7-hydroxycoumarin, as indicated by the earlier results, is likely via the indirect $\mathrm{O}_{2}$ pathway. Based upon this observation, it is likely the low yield of $\mathrm{OH}$ radicals is a result of competition for the conduction band electron between superoxide formation and $\mathrm{H}^{+}$ reduction to form $\mathrm{H}_{2}(0 \mathrm{~V}$ vs $\mathrm{NHE})$. In addition, since all these experiments were performed in a closed system with limited $\mathrm{O}_{2}$, a reducing catalyst such as $\mathrm{Pt}-\mathrm{C}_{3} \mathrm{~N}_{4}$ is expected to produce less $\mathrm{OH}$ radicals than an open system. Furthermore, despite a favourable particle size of $20-40 \mathrm{~nm}, \mathrm{Pt}_{-} \mathrm{C}_{3} \mathrm{~N}_{4}$ was observed to agglomerate to form larger aggregates leading to a decrease in surface area and in turn light absorption.

In the case of $\mathrm{LaCr}-\mathrm{SrTiO}_{3}, \mathrm{Cr}-\mathrm{SrTiO}_{3}$ and yellow $\mathrm{TiO}_{2}$, the electronic structures showed both the valence band and conduction band of all these catalysts to be lower than the redox potentials to facilitate radical formation as seen in Figure 6 . These catalysts were primarily used as a control parameter to ensure no 7-hydroxycoumarin formation was observed.

\section{The calculated $\mathrm{OH}$ radical concentrations and production rates produced over all} catalysts screened are summarised in Table 1. The results show that the activity of the visible light activated photocatalysts studied were significantly lower than commercial P25 under UV light. This further emphasises that although there are numerous visible light absorbing photocatalysts, their ability to produce $\mathrm{OH}$ radicals is significantly lower than P25. In future, if any visible light absorbing photocatalysts are to be fabricated for the purpose of photocatalytic oxidation, their $\mathrm{OH}$ radical producing rates (and quantities) should be determined and compared to P25 as demonstrated here. 


\section{CONCLUSION}

The aim of screening UV and visible light absorbing photocatalysts to assess their oxidative strength was accomplished successfully by trapping $\mathrm{OH}$ radicals produced by the photocatalysts in 7-hydroxycoumarin. The $\mathrm{OH}$ radical production capabilities of various photocatalysts covering a range of band gaps and particle sizes were assessed by comparing and discussing their differences with the commercial UV light activated P25. To conclude, visible light activated photocatalysts such as $\mathrm{LaCr}_{-} \mathrm{SrTiO}, \mathrm{Cr}-$ $\mathrm{SrTiO}_{3}$ and yellow $\mathrm{TiO}_{2}$ did not produce any $\mathrm{OH}$ radicals and this could be attributed to their electronic structure. Whereas, the (pseudo) maximum $\mathrm{OH}$ radical production rates of other visible light activated photocatalysts namely, $\mathrm{WO}_{3}(0.28 \mu \mathrm{M} / \mathrm{hr})$ and $\mathrm{Pt}-\mathrm{C}_{3} \mathrm{~N}_{4}$ $(0.886 \mu \mathrm{M} / \mathrm{hr})$ were found to be significantly lower when compared to the commercial UV light activated P25 photocatalyst (35.654 $\mu \mathrm{M} / \mathrm{hr})$. This method could be further exploited as novel photocatalysts are developed and to compare a range of P25 concentrations for $\mathrm{OH}$ radical production. This study further emphasises the challenges faced by the visible light photocatalysts for photocatalytic oxidation.

\section{ACKNOWLEDGEMENTS}

This work was supported by the Engineering and Physical Sciences Research Council (Project number EP/K036769/1), Robert Gordon University's IDEAS PhD studentship and Queen's University Belfast's PhD studentship. The author would also like to thank Professor A Prasanna de Silva, School of Chemistry and Chemical Engineering, Queen's University Belfast, for his valuable contribution during the progress meetings. Supporting data are openly available on Queen's University, 


\section{REFERENCES}

[1] A. Fujishima, K. Honda, Electrochemical Photolysis of Water at a Semiconductor Electrode, Nature. 238 (1972) 37-38.

[2] D.W. Bahnemann, L.A. Lawton, P.K.J. Robertson, The Application of Semiconductor Photocatalysis for the Removal of Cyanotoxins from Water and Design Concepts for Solar Photocatalytic Reactors for Large Scale Water Treatment, in: S.L. Suib (Ed.), New and Future Developments in Catalysis, 1st ed., Elsevier, Amsterdam, 2013, pp. 395-415.

[3] M.R. Hoffmann, S.T. Martin, W. Choi, D.W. Bahnemann, Environmental Applications of Semiconductor Photocatalysis, Chem. Rev. 95 (1995) 69-96.

[4] P.K.J. Robertson, J.M.C. Robertson, D.W. Bahnemann, Removal of microorganisms and their chemical metabolites from water using semiconductor photocatalysis, J. Hazard. Mater. 211-212 (2012) 161-171.

[5] H. Kominami, S. Murakami, M. Kohno, Y. Kera, K. Okada, B. Ohtani, Stoichiometric decomposition of water by titanium(IV) oxide photocatalyst synthesized in organic media: Effect of synthesis and irradiation conditions on photocatalytic activity, Phys. Chem. Chem. Phys. 3 (2001) 4102-4106.

[6] C. McCullagh, P.K.J. Robertson, M. Adams, P.M. Pollard, A. Mohammed, Development of a slurry continuous flow reactor for photocatalytic treatment of industrial waste water, J. Photochem. Photobiol. A. 211 (2010) 42-46.

[7] P.K.J. Robertson, Semiconductor photocatalysis: an environmentally acceptable alternative production technique and effluent treatment process, J. Clean. Prod. 4 (1996) 203-212.

[8] M. Adams, I. Campbell, C. McCullagh, D. Russell, D.W. Bahnemann, P.K.J. Robertson, From Ideal Reactor Concepts to Reality: The Novel Drum Reactor for Photocatalytic Wastewater Treatment, Int. J. Chem. React. Eng. 11 (2013) 621-632.

[9] O. Carp, C.L. Huisman, A. Reller, Photoinduced reactivity of titanium dioxide, Progress in Solid State Chemistry. 32 (2004) 33-177.

[10] C. McCullagh, N. Skillen, M. Adams, P.K.J. Robertson, Photocatalytic reactors for environmental remediation: a review, J. Chem. Technol. Biotechnol. 86 (2011) 10021017.

[11] J. Jiang, Z. Zhou, V.K. Sharma, Occurrence, transportation, monitoring and treatment of emerging micro-pollutants in waste water - A review from global views, Microchem. J. 110 (2013) 292-300.

[12] A. Asghar, A.A. Abdul Raman, W.M.A. Wan Daud, Advanced oxidation processes for in-situ production of hydrogen peroxide/hydroxyl radical for textile wastewater treatment: a review, J. Clean. Prod. 87 (2015) 826-838. 
[13] H. Fan, G. Li, F. Yang, L. Yang, S. Zhang, Photodegradation of cellulose under UV light catalysed by TiO2, J. Chem. Technol. Biotechnol. 86 (2011) 1107-1112.

[14] E. Szabó-Bárdos, K. Somogyi, N. Törő, G. Kiss, A. Horváth, Photocatalytic decomposition of I-phenylalanine over TiO2: Identification of intermediates and the mechanism of photodegradation, Appl. Catal. B: Environ. 101 (2011) 471-478.

[15] T. Hirakawa, K. Yawata, Y. Nosaka, Photocatalytic reactivity for O2- and $\mathrm{OH}$ radical formation in anatase and rutile $\mathrm{TiO} 2$ suspension as the effect of $\mathrm{H} 2 \mathrm{O} 2$ addition, Appl. Catal. A-Gen. 325 (2007) 105-111.

[16] Y. Nosaka, T. Daimon, A.Y. Nosaka, Y. Murakami, Singlet oxygen formation in photocatalytic TiO2 aqueous suspension, Phys. Chem. Chem. Phys. 6 (2004) 29172918.

[17] X. Yan, T. Ohno, K. Nishijima, R. Abe, B. Ohtani, Is methylene blue an appropriate substrate for a photocatalytic activity test? A study with visible-light responsive titania, Chemical Physics Letters. 429 (2006) 606-610.

[18] B. Ohtani, Preparing Articles on Photocatalysis-Beyond the Illusions, Misconceptions, and Speculation, Chem. Lett. 37 (2008) 216-229.

[19] A. Mills, An overview of the methylene blue ISO test for assessing the activities of photocatalytic films, Applied Catalysis B: Environmental. 128 (2012) 144-149.

[20] J. Kim, C.W. Lee, W. Choi, Platinized WO3 as an Environmental Photocatalyst that Generates OH Radicals under Visible Light, Environ. Sci. Technol. 44 (2010) 68496854.

[21] Q. Xiang, J. Yu, P.K. Wong, Quantitative characterization of hydroxyl radicals produced by various photocatalysts, J. Colloid Interface Sci. 357 (2011) 163-167.

[22] M. Sato, T. Ohgiyama, J.S. Clements, Formation of chemical species and their effects on microorganisms using a pulsed high voltage discharge in water, Industry Applications Society Annual Meeting. 2 (1994) 1455-1461.

[23] H. Czili, A. Horváth, Applicability of coumarin for detecting and measuring hydroxyl radicals generated by photoexcitation of TiO2 nanoparticles, Appl. Catal. B: Environ. 81 (2008) 295-302.

[24] R. Ono, T. Oda, Measurement of hydroxyl radicals in pulsed corona discharge, J. Electrostatics. 55 (2002) 333-342.

[25] W. Hoeben, E. van Veldhuizen, W. Rutgers, G. Kroesen, Gas phase corona discharges for oxidation of phenol in an aqueous solution, J. Phys. D: Appl. Phys. 32 (1999) 133-137.

[26] P. Sunka, V. Babický, M. Clupek, P. Lukes, M. Simek, J. Schmidt, M. Cern, Generation of chemically active species by electrical discharges in water, Plasma Sources Sci. Technol. 8 (1999) 258-265. 
[27] B. Sun, M. Sato, J. Sid Clements, Optical study of active species produced by a 473 pulsed streamer corona discharge in water, J. Electrostatics. 39 (1997) 189-202.

474 [28] M.G. Steiner, C.F. Babbs, Quantitation of the hydroxyl radical by reaction with 475 dimethyl sulfoxide, Arch. Biochem. Biophys. 278 (1990) 478-481.

476 [29] M. Sahni, B.R. Locke, Quantification of Hydroxyl Radicals Produced in Aqueous 477 Phase Pulsed Electrical Discharge Reactors, Ind. Eng. Chem. Res. 45 (2006) 58194785825.

479 [30] J. Ku, E. Zimowski, United States Department of Labor, Occupational Safety and 480 Health Administration. 3M Formaldehyde Monitor (Model 3721), Product evaluation 481 (PE-10). 205 (1989).

482 [31] S.A.V. Eremia, D. Chevalier-Lucia, G. Radu, J. Marty, Optimization of hydroxyl 483 radical formation using $\mathrm{TiO} 2$ as photocatalyst by response surface methodology, 484 Talanta. 77 (2008) 858-862.

[32] T. Maezono, M. Tokumura, M. Sekine, Y. Kawase, Hydroxyl radical concentration profile in photo-Fenton oxidation process: Generation and consumption of hydroxyl radicals during the discoloration of azo-dye Orange II, Chemosphere. 82 (2011) 14221430.

[33] M. Tokumura, R. Morito, R. Hatayama, Y. Kawase, Iron redox cycling in hydroxyl radical generation during the photo-Fenton oxidative degradation: Dynamic change of hydroxyl radical concentration, Appl. Catal. B: Environ. 106 (2011) 565-576.

[34] S. Kanazawa, T. Furuki, T. Nakaji, S. Akamine, R. Ichiki, Measurement of $\mathrm{OH}$ Radicals in Aqueous Solution Produced by Atmospheric-pressure LF Plasma Jet, I. J. PEST. 6 (2012) 166-171.

[35] K. Ishibashi, A. Fujishima, T. Watanabe, K. Hashimoto, Quantum yields of active oxidative species formed on TiO2 photocatalyst, J. Photochem. Photobiol. A. 134 (2000) 139-142.

[36] T. Hirakawa, Y. Nosaka, Properties of O2.- and OH. Formed in TiO2 Aqueous Suspensions by Photocatalytic Reaction and the Influence of $\mathrm{H} 2 \mathrm{O} 2$ and Some lons, Langmuir. 18 (2002) 3247-3254.

[37] Z. Li, T. Liang, S. Lv, Q. Zhuang, Z. Liu, A Rationally Designed Upconversion Nanoprobe for in Vivo Detection of Hydroxyl Radical, J. Am. Chem. Soc. 137 (2015) 11179-11185.

[38] J. Zhang, Y. Nosaka, Quantitative Detection of OH Radicals for Investigating the Reaction Mechanism of Various Visible-Light TiO2 Photocatalysts in Aqueous Suspension, J. Phys. Chem. C. 117 (2013) 1383-1391.

[39] M.E. Lindsey, M.A. Tarr, Quantitation of hydroxyl radical during Fenton oxidation following a single addition of iron and peroxide, Chemosphere. 41 (2000) 409-417. 
509 [40] J. Zhang, Y. Nosaka, Generation of $\mathrm{OH}$ radicals and oxidation mechanism in 510 photocatalysis of WO3 and BiVO4 powders, J. Photochem. Photobiol. A. 303-304 511 (2015) 53-58.

512 [41] F. Fina, H. Menard, J.T.S. Irvine, The effect of Pt NPs crystallinity and distribution 513 on the photocatalytic activity of Pt-g-C3N4, Phys. Chem. Chem. Phys. 17 (2015) 514 13929-13936.

515 [42] C. Randorn, J.T.S. Irvine, P. Robertson, Synthesis of Visible-Light-Activated 516 Yellow Amorphous Photocatalyst, Int. J. Photoenergy. 2008 (2008) 1-6.

517 [43] S. Ouyang, H. Tong, N. Umezawa, J. Cao, P. Li, Y. Bi, Y. Zhang, J. Ye, Surface518 Alkalinization-Induced Enhancement of Photocatalytic H2 Evolution over SrTiO3-Based 519 Photocatalysts, J. Am. Chem. Soc. 134 (2012) 1974-1977.

520 [44] M. Muralidharan, V. Anbarasu, A. Elaya Perumal, K. Sivakumar, Carrier mediated (2015) 6352-6365.

[45] J. Guo, Y. Li, S. Zhu, Z. Chen, Q. Liu, D. Zhang, W. Moon, D. Song, Synthesis of WO3@Graphene composite for enhanced photocatalytic oxygen evolution from water, RSC Adv. 2 (2012) 1356-1363.

[46] K. van Benthem, C. Elsässer, R.H. French, Bulk electronic structure of SrTiO3: Experiment and theory, J. Appl. Phys. 90 (2001) 6156-6164.

[47] J. Kamalakkannan, V.L. Chandraboss, S. Prabha, S. Senthilvelan, Advanced construction of heterostructured InCrO4-TiO2 and its dual properties of greater UVphotocatalytic and antibacterial activity, RSC Adv. 5 (2015) 77000-77013.

[48] M. Wojtoniszak, B. Zielinska, R.J. Kalenczuk, E. Mijowska, Photocatalytic performance of titania nanospheres deposited on graphene in coumarin oxidation reaction, Materials Science-Poland. 30 (2012) 32-38.

[49] G. Li, K.H. Wong, X. Zhang, C. Hu, J.C. Yu, R.C.Y. Chan, P.K. Wong, Degradation of Acid Orange 7 using magnetic $\mathrm{AgBr}$ under visible light: The roles of oxidizing species, Chemosphere. 76 (2009) 1185-1191.

[50] J. Zhang, Y. Nosaka, Mechanism of the OH Radical Generation in Photocatalysis with TiO2 of Different Crystalline Types, J. Phys. Chem. C. 118 (2014) 10824-10832.

[51] H. Guan, L. Zhu, H. Zhou, H. Tang, Rapid probing of photocatalytic activity on titania-based self-cleaning materials using 7-hydroxycoumarin fluorescent probe, Anal. Chim. Acta. 608 (2008) 73-78.

[52] Z. Huang, Q. Sun, K. Lv, Z. Zhang, M. Li, B. Li, Effect of contact interface between $\mathrm{TiO} 2$ and $g$-C3N4 on the photoreactivity of $g$-C3N4/TiO2 photocatalyst: $\left(\begin{array}{lll}0 & 0 & 1\end{array}\right)$ vs $\left(\begin{array}{ll}1 & 0\end{array}\right.$ 1) facets of TiO2, Applied Catalysis B: Environmental. 164 (2015) 420-427.

[53] P.M. Wood, The potential diagram for oxygen at pH 7, Biochem. J. 253 (1988) 287-289. 
547 [54] G. Zhang, Z. Lan, L. Lin, S. Lin, X. Wang, Overall water splitting by Pt/g-C3N4 548 photocatalysts without using sacrificial agents, Chem. Sci. 7 (2016) 3062-3066. 
550 List of Captions for figures and tables.

551 Figure 1: XRD profiles of photocatalysts representing the plane indices $[44,45]$.

552 Figure 2: UV-Visible absorption spectra of photocatalysts

553 Figure 3: Coumarin and 7-hydroxycoumarin profiles of $100 \mathrm{ml}$ of $100 \mu \mathrm{M}$ coumarin with $5540.1 \mathrm{~g} / \mathrm{L}$ P25 under 36 W UV light

555 Figure 4: Coumarin profiles of $100 \mathrm{ml}$ of $100 \mu \mathrm{M}$ coumarin with $0.1 \mathrm{~g} / \mathrm{L}$ visible light 556 photocatalysts; Inset: coumarin profiles of $\mathrm{WO}_{3}$ and $\mathrm{Pt}^{-\mathrm{C}_{3} \mathrm{~N}_{4}}$

557 Figure 5: 7-hydroxycoumarin production profiles of $100 \mathrm{ml}$ of $100 \mu \mathrm{M}$ coumarin with 0.1 $558 \mathrm{~g} / \mathrm{L}$ visible light photocatalysts

559 Figure 6: Electronic structure of the photocatalysts used

560

561 Table 1: Pseudo maximum $\mathrm{OH}$ radical production rates and quantities.

562

563 

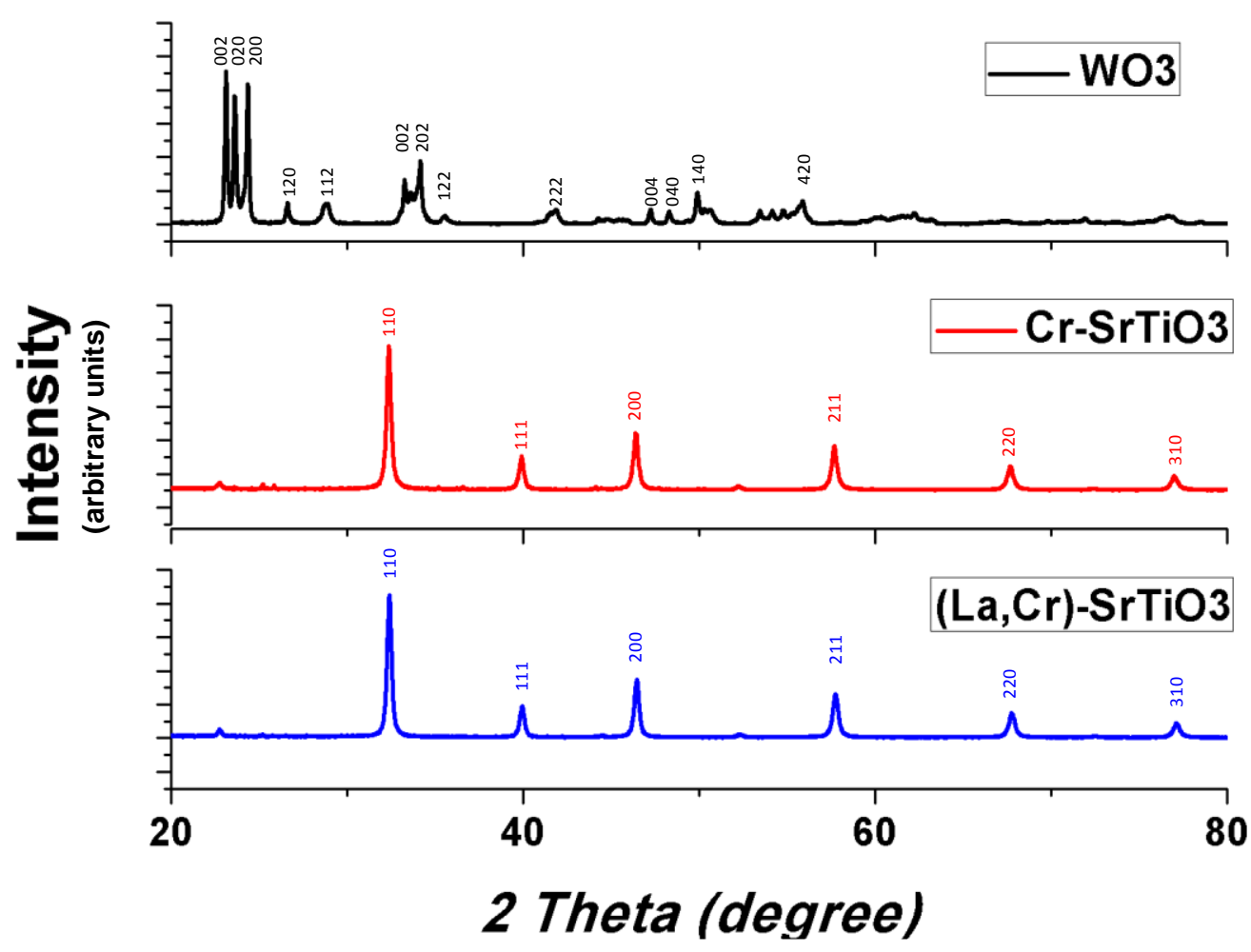

Figure 1

566

567

568

569 


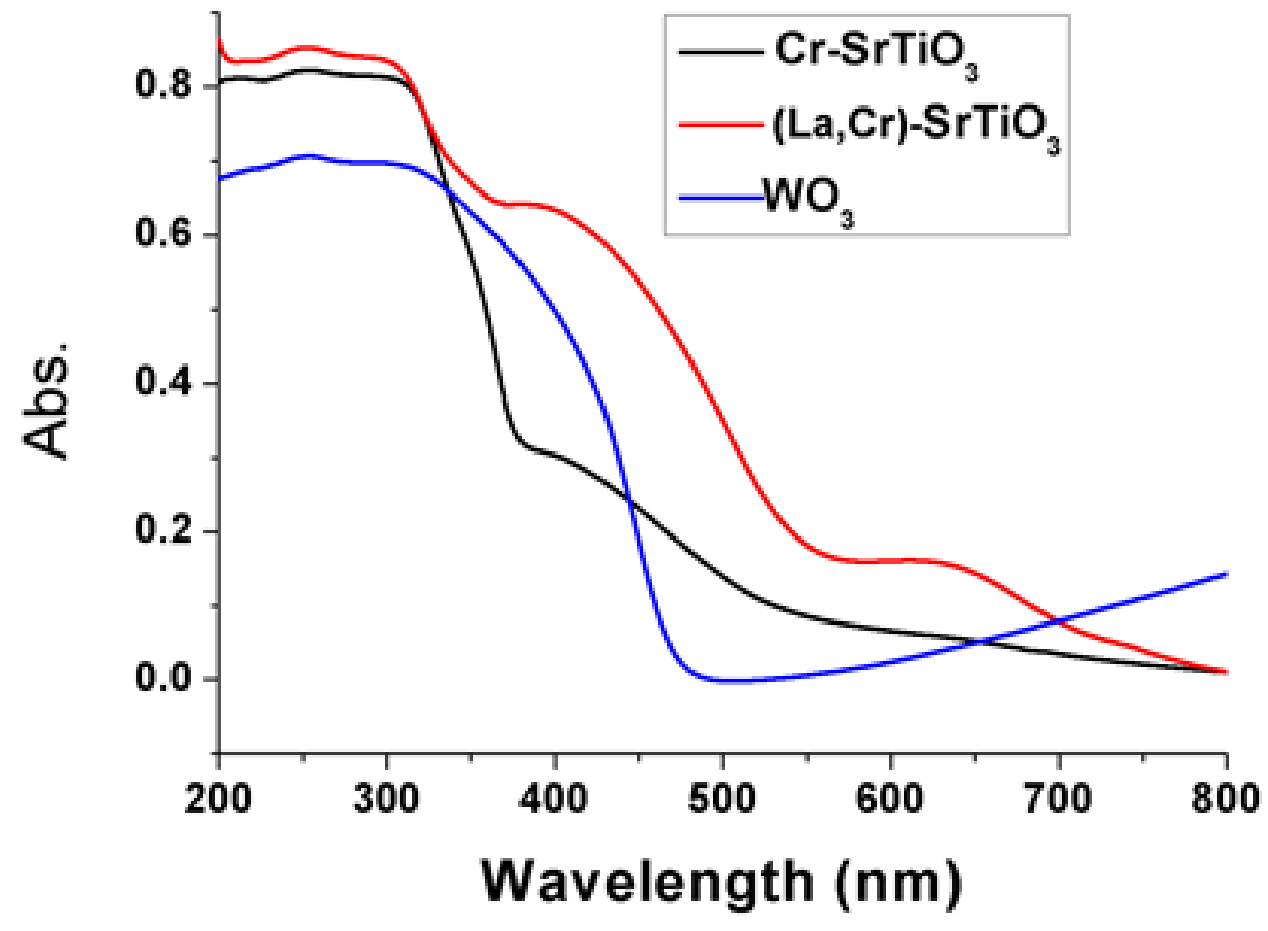

570

Figure 2

572

573

574

575

576

577 


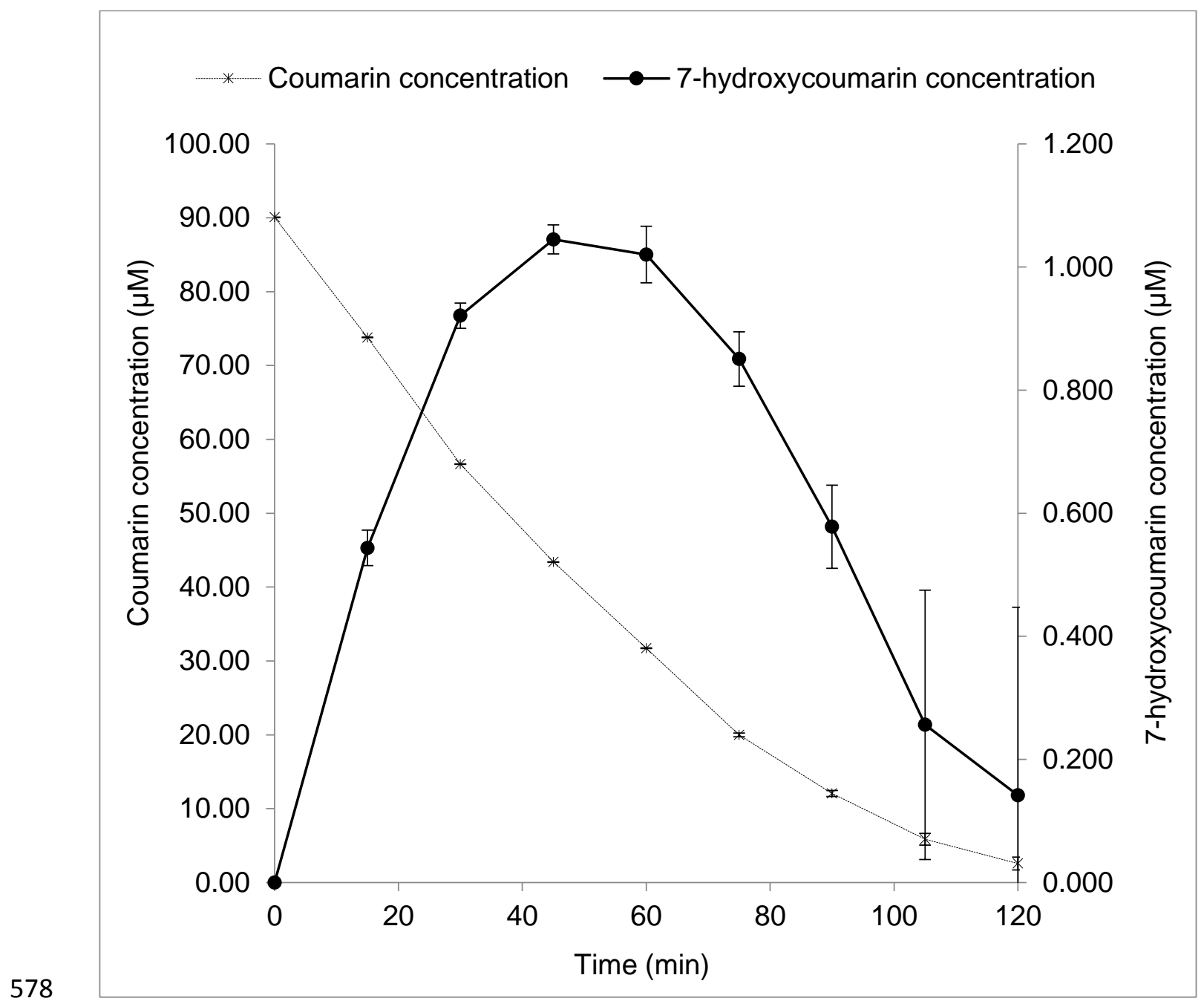

$579 \quad$ Figure 3 


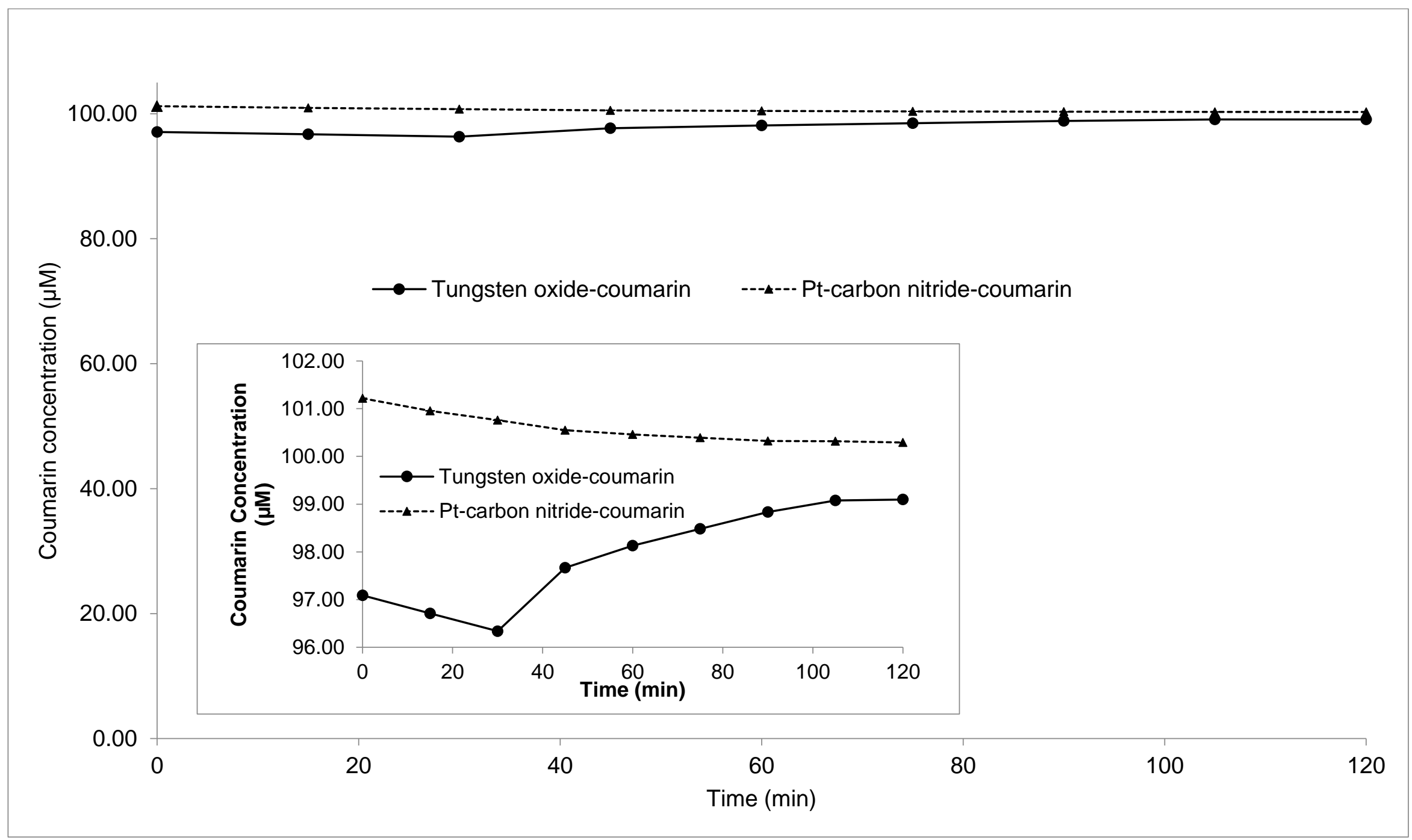

580

Figure 4 
582

583

584

585

586

587

588 589 590

591 592 593 594 595

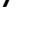

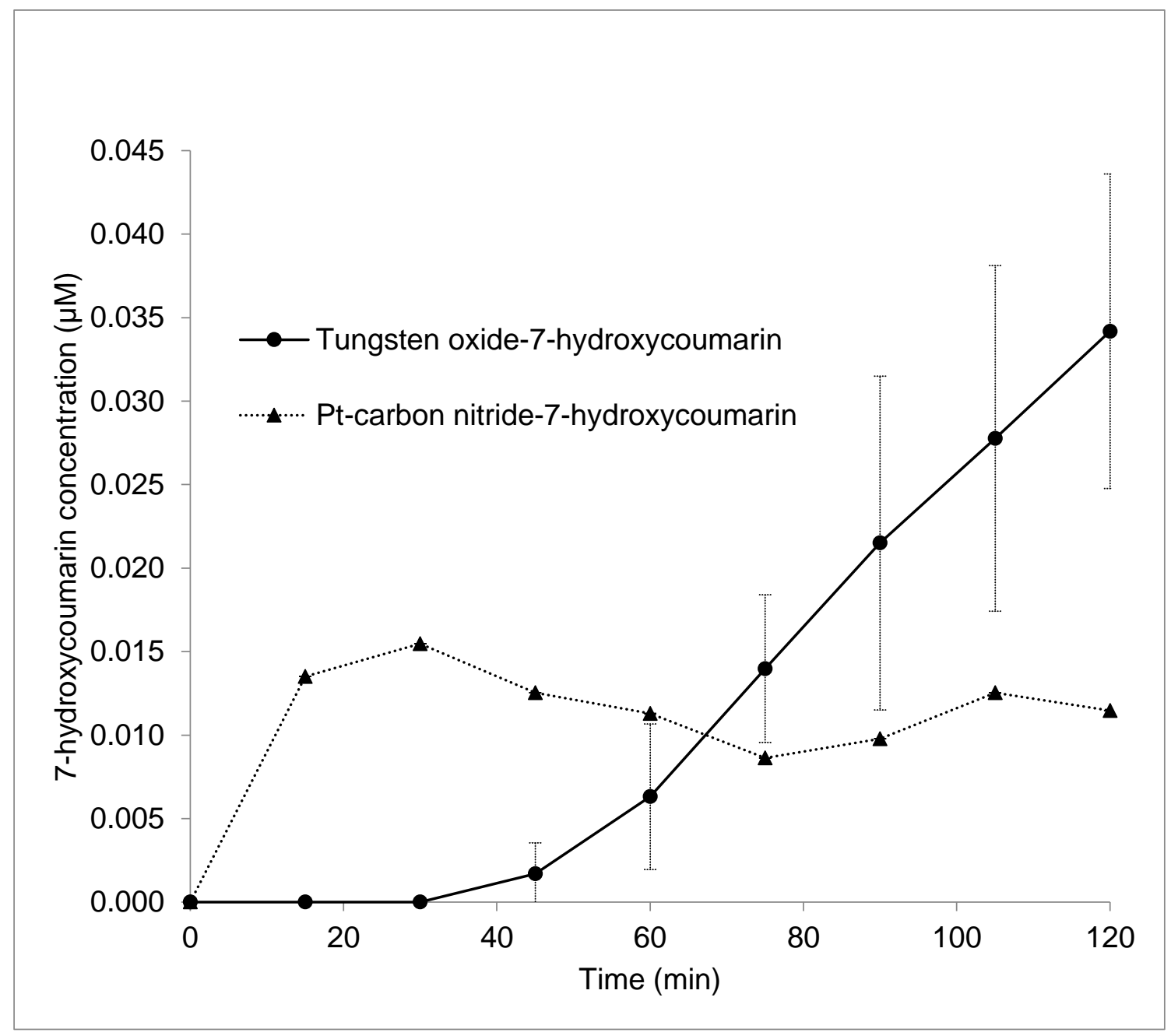

Figure 5

\section{5}

(2)




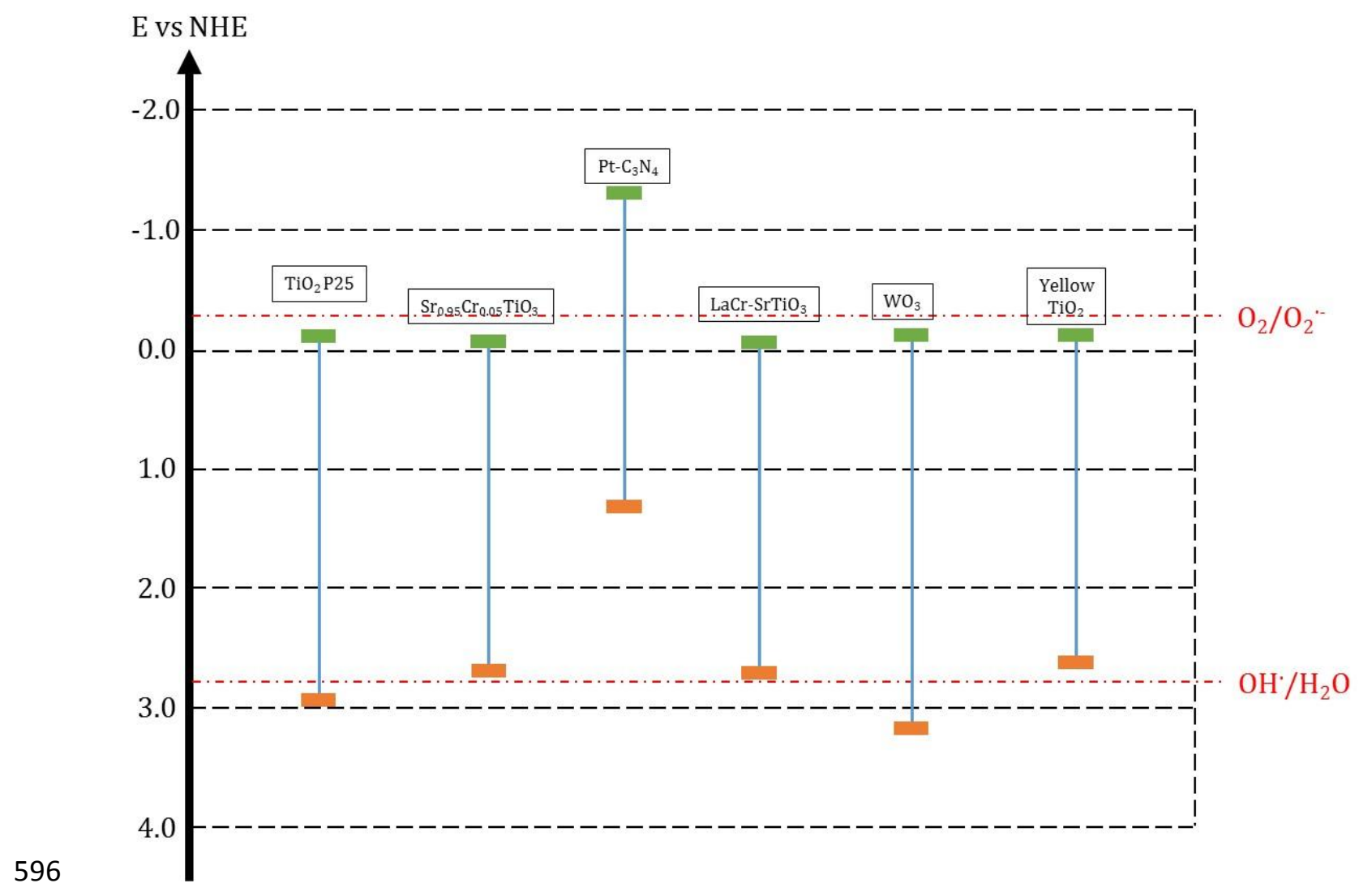

597

598

Figure 6

599

600

601

602

603

604

605

606

607

608 


\begin{tabular}{|l|l|l|l|l|}
\hline & Photocatalyst & $\begin{array}{l}\text { Light } \\
\text { Source } \\
\text { radical } \\
\text { concentration } \\
(\mu \mathrm{M})\end{array}$ & $\begin{array}{l}\text { Time at which } \\
\text { maximum } \\
\text { concentration } \\
\text { of OH radical } \\
\text { was } \\
\text { produced } \\
(\mathbf{m i n})\end{array}$ & $\begin{array}{l}\text { Maximum } \\
\text { OH radical } \\
\text { production } \\
\text { rate } \\
(\mu \mathrm{M} / \mathrm{hr})\end{array}$ \\
\hline $\mathrm{P} 25$ & UV & 16.9 & 45 & 35.654 \\
\hline $\mathrm{WO}_{3}$ & visible & 0.560 & 120 & 0.280 \\
\hline $\mathrm{Pt}_{-} \mathrm{C}_{3} \mathrm{~N}_{4}$ & visible & 0.254 & 30 & 0.886 \\
\hline
\end{tabular}

609

610 Table 1 